\title{
Ozone application to extend shelf life of vegetables by microbial growth inhibition
}

\author{
$A$ I Susan ${ }^{1, *}, E$ Sasmita $^{1}, E$ Yulianto $^{1}, F$ Arianto $^{1,2}, M$ Restiwijaya $^{1}, A W$ Kinandana $^{1}$, and $M$ Nur $^{1,2}$ \\ ${ }^{1}$ Diponegoro University, Center for Plasma Research, Faculty of Science and Mathematics, Semarang, Indonesia \\ ${ }^{2}$ Diponegoro University, Physics Department, Faculty of Science and Mathematics, Semarang, Indonesia
}

\begin{abstract}
Ozone has been used to extend the shelf life of vegetables by inhibiting the decomposing microbial growth. The study was conducted using six types of vegetables; i.e. broccoli, tomato, mustard, celery, leek, and lettuce; treated and stored using ozonation techniques. The six types of vegetables were divided into two treatment groups, i.e. ozone-washed and not washed, and stored in ozone-filled cold storage at a dose of $15 \mathrm{gr} / \mathrm{m}^{3}$ per day. Total microbial testing was performed to determine the number of microbes in each vegetable sample. In addition, proximate testing was performed to observe the decreasing rate in nutrient content during storage time. The results showed that ozone-washed tomatoes is the most durable varieties which can stay fresh until day-12 with TPC and YMC values of $4.8 \times 10^{5} \mathrm{CFU} / \mathrm{g}$ and $13 \times 10^{5} \mathrm{CFU} / \mathrm{g}$ respectively. While the control tomato has a TPC and YMC value of $2.0 \times 10^{6} \mathrm{CFU} / \mathrm{g}$ and $85 \times 10^{6} \mathrm{CFU} / \mathrm{g}$ respectively. In addition, the proximate test results showed that the nutrient content in each ozone-washed samples didn't decrease significantly compared with the control samples. These results indicate that ozone-washing treatment can extend the shelf life of vegetables while still maintaining their nutritional value.
\end{abstract}

\section{Introduction}

Vegetables are important nutritional suppliers for human health, which can reducing the risk of dangerous diseases and other medical conditions [1-2]. Worldwide vegetables consumption reached $134 \mathrm{~kg}$ in 2013, increased by $0.6 \%$ from previous year [3]. Desire for year-round availability, increased diversity, and growing health awareness, have been important reasons for increased consumption of vegetables in around the world. Storage of vegetables is very important to ensure steady supply in accordance with fluctuations in daily demand and for supplying product even after the harvest season [4]. Various methods to extend the freshness of horticultural products have been applied in the food industries, including the most common is cold storage, controlled atmosphere (CA), and reduced pressure storage methods. While the very newest and advance food storing method is with ozone. Ozone has been widely applied in the food industry as a disinfectant agent, has better antimicrobial properties than chlorine. Following the affirmation of ozone as a GRAS (Generally Recognised as Safe) chemical in 1997, US FDA then approved ozone as a safe antimicrobial additive for direct contact with all types of food [5-7]. Ozone is in the gaseous phase at room and refrigeration temperature and it is partially soluble in water. Ozone is relatively stable in air but highly unstable in aqueous solutions. Ozone is autodecomposed continuously but slowly into oxygen, according to a pseudo first-order reaction, and thus it leaves no residues in food [8-9].

The microbial inactivation activities by ozone in vegetables has been intensively studied [10-15]. When it comes to deal with the fast-food business, catering companies, and fresh-cut vegetables industries, the washing process is mainly required to be involved in order to meet the standard hygiene procedure [16]. Therefore, a new technic involving washing process is urgently required to improve inactivation of hazard pathogen while maintaining the sensory quality of vegetables. Ozone is recognized as safe to applied, both directly and indirectly, to disinfect fruit and vegetables [17]. As indirect application, ozone is commonly dissolving into water then producing an ozonated water. This study is focusing in the used of ozonated water in vegetables treatment, combined with ozone exposure directly in a cold storage system. This integrated treatment system is expected to maximize the ozone efficacy in microbial inactivation, then in turn extending the shelf life of vegetables.

\section{Methods}

This research was conducted to determine the effect of ozone-washing treatment to the shelf life of vegetables compared to common ozone treatment without involving ozone-washing process. Fig.1 shows a series of ozonizing process in vegetables conducted by four

\footnotetext{
* Corresponding author: adeika.susan@st.fisika.undip.ac.id
} 
treatment steps; i.e. dissolving ozone to water, washing vegetables using ozonized water, drying the vegetables, and storing the vegetables in the cold storage equipped with ozonizing system. Ozone was produced by a dielectric barrier discharge (DBD) plasma reactor configured in a compact ozone generator comprising three main parts, i.e. ozone reactor, air pump, and AC high voltage. The generator produced ozone capacity of approximately $150 \mathrm{gr} /$ hour. As a preparation, ozone was dissolved in water, with temperature of about $21^{\circ} \mathrm{C}$, for about 1 hour in order to decontaminate the water from bacterial and reach a range dissolved ozone concentration of about 2.5 to $3 \mathrm{ppm}$.

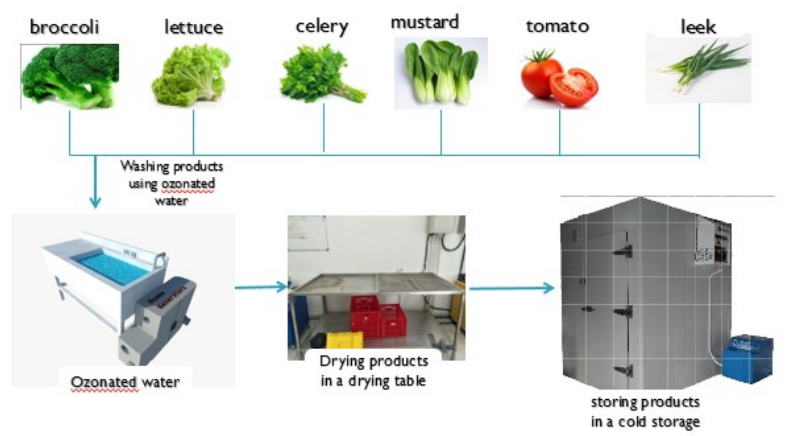

Fig. 1. A series of ozonation process in vegetables.

The research was conducted using six types of vegetable: i.e. broccoli, tomato, mustard, celery, lettuce, and leek. Each types of vegetables was divided into two groups of treatment; i.e. ozone-washed and not ozonewashed, and the both groups of vegetables then stored in an ozone-dedicated cold storage. Ozone was delivered to the cold storage with the density of $15 \mathrm{gr} / \mathrm{m}^{3}$ per day during the storage time. The temperature of cold storage was set in the range of 2 to $7^{\circ} \mathrm{C}$, whereas the average temperature measured in the cold storage is about $5^{\circ} \mathrm{C}$, while the measured relative humidity $(\mathrm{RH})$ was in the range of 90 to $99 \%$.

The effect of ozone treatment to the shelf life of vegetables was observed by using total microbial test, through TPC (total plate count) and YMC (yeast and mold count) tests, which is the major factor causing decay. In addition, proximate test; comprising carbohydrate, protein, fat, water, ash, and vitamin B1; was conducted to observe the nutritional content in vegetables as a function of storage time. The storage has stopped based on the freshness observation results, when the stored vegetables has shrivel, browning, having bad smell, and slimy, than indicated that the vegetable has decay and the storage must to be stopped.

\section{Results and Discussion}

\subsection{Total microbial test results}

Based on the microbial test results, through TPC and YMC tests, obtained that total of microbes in the six type used in this study were increase with the increasing of storage time. However, the number of microbes in the ozone-washed samples were always lower than that in not ozone-washed samples. Fig. 2 showed the TPC and YMC graphics in the six types of vegetables.

At the first treatment day, the TPC and YMC values in the vegetables samples were in the range of $5 \mathrm{log}$ and $4 \mathrm{log}$, respectively. Ozone-washing treatment can decrease TPC value by 1 to $2 \log$ from that contained in control samples on the first day become in the range of 3 $\log$; in celery, lettuce, broccoli, and tomato; and by 4 log; in leek and mustard. While the YMC content in ozone-washed samples on the first treatment day was reduced by 1 to $2 \log$ from that contained in the control samples become in the range of $\log 4$ and 5 (as shown in fig.2 and fig.3). Ozone as an antimicrobial agent can inhibit the microbial growth in various food products, including in fruits and vegetables. A direct application of ozone in lettuce showed inactivation of $\mathrm{E}$. coli was approximately $1.6 \mathrm{log}$ after exposed by $5.2 \mathrm{mg} / \mathrm{L}$ ozone gas [18]. Meanwhile, tomatoes showed the bacterial inactivation of $2.2 \mathrm{log}$ reduction after 15 minutes exposed [12].

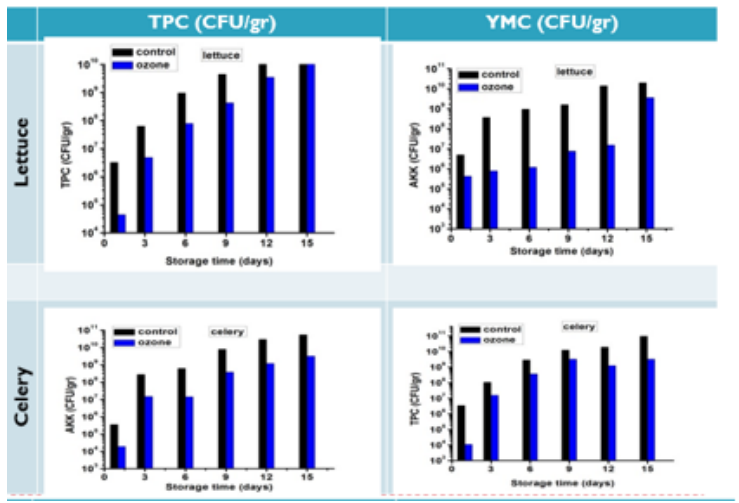

Fig. 2. Graphics of TPC and YMC containted in (a) lettuce, and (b) celery.

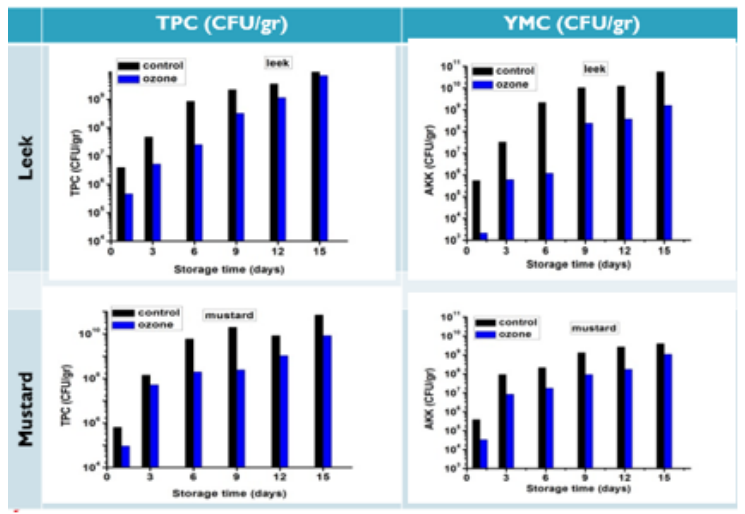

Fig. 3. Graphics of TPC and YMC containted in (a) leek, and (b) mustard.

Furthermore, on the day- 6 of storing, the TPC and YMC in not ozone-washed samples had reached $\log 7$, while in the ozone-washed samples was in the $6 \mathrm{log}$. Meanwhile, the TPC and YMC values in not ozonewashed broccoli on the day- 6 has reached $8 \log$ while in the ozone-washed broccoli has reached $7 \mathrm{log}$. The high value of total microbial has causing the decay in broccoli 
faster than other vegetables commodity. Those results is in accordance with the visually freshness appearance, whereas on the day- 6 the broccoli samples was browning and no more fresh, so that the storing treatment for broccoli was stopped on the day-7. These results showed that broccoli is the commodity with shortest shelf life, which only can survive until day-6. The decaying process in broccoli started even after harvest indicated by Floret yellowing [19]. Respiration rate during postharvest storage of vegetables leads the degradation of chlorophyll level resulting floret yellowing or browning [20-21]. The quality loss occured due to increases in amino acids is mainly caused by losses of sugar, ascorbic acid, and protein degradation in vegetables [21-23].

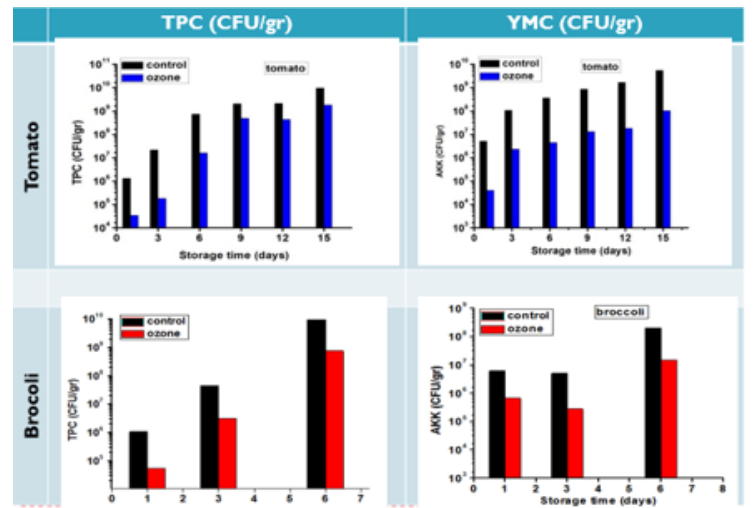

Fig. 4. Graphics of TPC and YMC containted in (a) tomato, and (b) broccoli.

Based on the visually freshness appearance, the four not ozone-washed samples; i.e. celery, leek, mustard, and lettuce; can stay fresh until the day- 6 with the TPC were reaching 7 and $8 \log$ while the YMC were reaching $\log 7$. However, the ozone washed samples of the same four vegetable types can stay fresh until day-9 with the TPC and YMC were in the range of $\log 7$ and $\log 8$ respectively. In the other side, tomato is the most durable than other commodities used in this research. The visually freshness appearance in tomato, both ozonewashed and not ozone washed, showed that tomato can stay fresh until day-12 with the TPC and YMC on not ozone-washed samples of 2.0x106 CFU/g and 85x106 $\mathrm{CFU} / \mathrm{g}$ respectively, while on the ozone-washed samples the TPC and YMC of $4.8 \times 105 \mathrm{CFU} / \mathrm{g}$ and $13 \times 105$ CFU/g respectively (as shown in Fig.3.3.). Those results were in accordance to the visually freshness appearance observation, whereas the both groups of tomato samples still look fresh and having fresh flavor even until 15 days storing. However, the storing treatment for five types of vegetable; i.e. mustard, celery, leek, lettuce, was stopped on the day-16.

As a free radical, ozone is able to oxidize and destroy the cell walls, penetrating the cytoplasmic membrane to ultimately damage its genetic structure of a bacteria. Furthermore, when the bacterial DNA is damaged then the bacteria will not be able to develop the immune system against ozone, which is an advantage and distinct antimicrobial properties of ozone (Cullen et al., 2010; Naito \& Takahara, 2006, Xu, 1999).

\subsection{Proximate test results}

Nutritional content in vegetables was determined through proximate testes including: water, ash, carbohydrate, fat, protein, and vitamin B1 contents. Generally, proximate test results showed that the nutritional content in each vegetable decrease with the increase of storing duration. In addition, the nutritional content in ozone-washed vegetables were tend to higher than that in not ozone-washed samples.

\subsubsection{Water content}

Determination of water content is one of the important and most common analysis conducted in the food processing and test. The number of dry matter of a sample is reversely indicating the number of water contained, therefore the water content was directly linked to the matter's economical value. The water contained in a matter was also linked to the stability and quality of the matter. The water content is necessary to determined in order to obtain the nutritional content of food, to meet the composition standards and regulation for food. The water content was also necessary to calculate the ingredient composition served based on the dry-matter.

In this research, there's no significantly different of water content on the day- 6 between not ozone-washed and ozone washed vegetable samples, as shown in the graphics in Fig.5. However, the water content in not ozone-washed samples were higher than that in ozonewashed samples, but the different is very small. The water content in all types of vegetables used in this research can be maintained until day-15, this due to the controlled humidity in the cold storage. The humidity in the cold storage was controlled in the range of 90 to $99 \%$, with the average humidity is approximately of $95 \%$. The relatively high humidity has causing the stored vegetables having high water content and made the vegetables longer fresh.

\subsubsection{Ash content}

The number of ash in food is important to determine the BETN (non nitrogen extract matter) value. The ash content in a food matter is represent the mineral content. Ash content in all types of vegetables used in this research were tend to decrease with the increase of storage duration. However, the results obtained showed that ozone-washed vegetables have higher ash content than that in not ozone-washed during the storage time. Those results indicate that washing treatment using ozonated water can supress the ash content degradation in vegetables, it means that mineral content in vegetables can be longer maintained. On the first treatment day, the ash content in ozone-washed samples were tent to lower than that in not ozone-washed, it indicates that there are a few number of mineral dissolved or lost in water due to washing process. However, the ash content degradation due to washing process was detected only in very small number, that is about $0.01 \%$ to $0.05 \%$. 


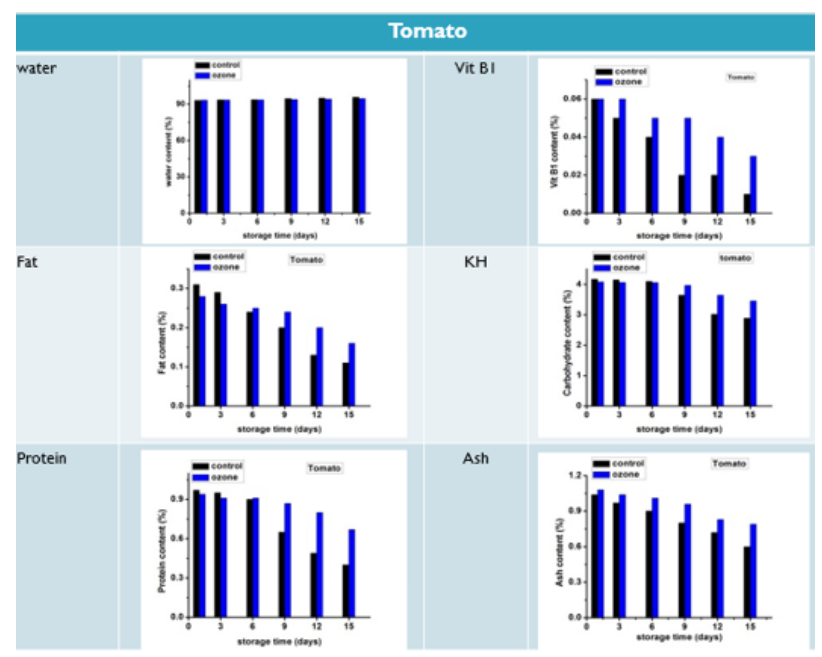

Fig. 5. Nutritional content in tomato. Tomato is the most durable which can stay fresh until 15 days.

\subsubsection{Fat content}

Fat content in the six types of vegetables have the similar degradation pattern during storage time until the day-15. The fat content decrease with the increase of storage duration. Based on the graphics of fat content as a function of storage time, it was obtained that the fat content degradation in not ozone-washed samples were significantly higher than that in ozone-washed samples. These results showed that the fat content in ozonewashed vegetables were higher than that in not ozonewashed vegetables. Leek has the highest fat content than the other five vegetables, that is $0.66 \%$ and $0.68 \%$ for control and ozone washed samples respectively. Beside it, control broccoli and celery have the lowest fat content when compared to other types of vegetables used in this study, of $0.08 \%$. The longer storage time causing the more degradation of fat content in all types of vegetables. After 15 days storage, the highest degradation of fat content was obtained in leek, both not ozone-washed and ozone-washed, of $0.47 \%$ and 0.27 respectively. Meanwhile, the lowest degradation was obtained in celery after stored 15 days, of $0.07 \%$ and $0.05 \%$ in the not ozone-washed and ozone-washed samples, respectively.

\subsubsection{Protein content}

Protein content in all six types of vegetables decrease with the increase of storage duration. The longer storage time causing the highest decrease of protein content, with the lowest protein level contained in the vegetables stored for 15 days. However, the protein content of ozone-washed samples have tend to higher than that in not ozone-washed samples. Mustard has the highest protein content compared to other five types of vegetable, of 2.24 and 2.25 in not ozone-washed and ozone-washed samples, respectively on the first treatment day. The highest degradation of protein content was obtained in leek after stored for 15 days, of $0.95 \%$ and $0.74 \%$ in not ozone-washed and ozone- washed samples, respectively. Furthermore, the lowest degradation was obtained in lettuce with the degradation of 0.39 and $0.42 \%$ in not ozone-washed and ozonewashed samples respectively after stored for 15 days. Tendency that protein level contained in the ozonewashed samples was higher than that in not ozonewashed, it indicated that ozone-washing treatment can better maintain the protein content in vegetables compared to the common ozone treatment without involving ozone-washing process.

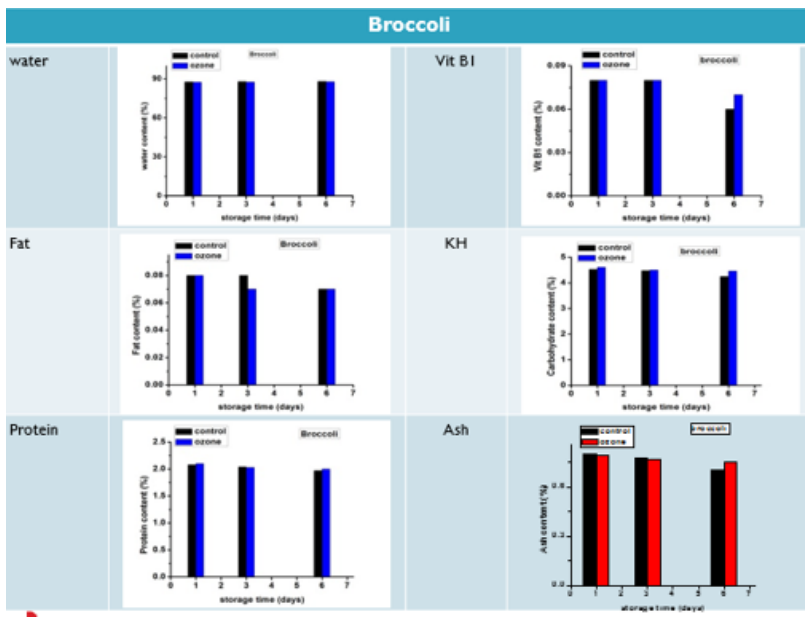

Fig. 6. Nutritional content in broccoli. Broccoli has shortest shelf life which can stay fresh only for 6 days.

\subsubsection{Carbohydrate content}

Broccoli has the highest carbohydrate content compared to other five types of vegetable, of 4.53 and $4.61 \%$ in the not ozone-washed and ozone-washed samples, respectively. Meanwhile, lettuce has the lowest carbohydrate level of 2.87 and $2.84 \%$ in the not ozonewashed and ozone-washed samples, respectively. The highest degradation of carbohydrate contained was obtained in celery after stored for 15 days of 1.50 and $0.67 \%$ in the not ozone-washed and ozone-washed samples, respectively. Besides, the lowest degradation was obtained in the leek samples after stored for 15 days of 0.68 and $1.07 \%$ in the not ozone-washed and ozonewashed samples, respectively. The carbohydrate content in the six types of vegetables used in this study has decreased with the increase of storage duration. The longer storage time causing the higher degradation of carbohydrate content. However, the ozone-washed vegetables samples was tend to can better and longer maintain their carbohydrate content, these results is in accordance with the higher carbohydrate content in the ozone-washed samples than that in not ozone-washed samples.

\subsubsection{Vitamin B1 content}

Each type of vegetable has distinctive vitamin B1. Mustard has the highest vitamin B1 content of 101 and $104 \mathrm{mg} / 100 \mathrm{gr}$ in the not ozone-washed and ozonewashed samples, respectively on the first day of 
treatment. In the other side, celery has the lowest vitamin B1 content of 0.02 and $0.03 \mathrm{mg} / 100 \mathrm{gr}$ in the not ozonewashed and ozone-washed samples, respectively on the first day of treatment. However, the lowest degradation of vitamin B1 was also occurred in mustard of $17.84 \%$ and $9.60 \%$, in the not ozone-washed and ozone-washed samples respectively on the day-15 from the first day of treatment. While the higher degradation of vitamin B1 was occurred in not ozone-washed tomato of $83.33 \%$ on the day-15 from the first day of treatment. The vitamin B1 content in all types of vegetable used in this study has decreased with the increase of storage time. The higher degradation of vitamin B1 content has occurred with the longer storage time. In addition, the vitamin B1 test on the all six types of vegetables showed that ozonewashing treatment can maintain the vitamin B1 content better and longer than that in common ozone treatment without involving ozone-washing process. These results is in accordance to the higher vitamin B1 content in ozone-washed samples than that in not ozone-washed samples.

\section{Conclusions}

Ozone treatment in vegetables has been proven can extend the shelf life of vegetables by inhibiting the microbial growth causing decay. The microbial test results, based on TPC and YMC tests, showed that ozone-washed treatment can suppress the microbial growth better than common ozone treatment without involving the washing process using ozonated water. Total of microbes contained in the ozone-washed samples is lower than that in not ozone-washed samples. The results showed that ozone-washed tomatoes is the most durable commodity which can stay fresh until the day-12, with TPC and YMC values of $4.8 \times 10^{5} \mathrm{CFU} / \mathrm{g}$ dan $13 \times 10^{5} \mathrm{CFU} / \mathrm{g}$ respectively. Beside it, broccoli is the commodity with shortest shelf life which only can stay until the day- 6 . In the not ozone-washed broccoli, the TPC and YMC contained on the day- 6 were reaching $9.7 \times 10^{8} \mathrm{CFU} / \mathrm{gr}$ dan $2.04 \times 10^{6} \mathrm{CFU} / \mathrm{gr}$ respectively. In addition, the TPC and YMC values in ozone-washed broccoli on the day- 6 were reaching $7,7 \times 10^{7}$ dan $1.5 \times 10^{5} \mathrm{CFU} / \mathrm{gr}$ respectively.

Furthermore, the proximate test results showed the advantages of washed treatment in vegetables using ozonated water compared to common ozone treatment without involving ozone-washed process. It can be showed from the proximate graphics, the nutrient content in ozone-washed vegetables were higher than that in not ozone-washed samples. In addition, the degradation pattern of nutritional content in ozone-washed samples was tent to lower than that in not ozone-washed samples, even until storage day-15. These results showed that ozone-washing can better maintain the nutritional content in vegetables than that in not ozone-washed samples. The ozone-washing can suppress the degradation of nutritional content in vegetables samples.

The authors would like to acknowledge to the The Ministries of Research, Technology, and Higher Education Republic Of
Indonesia (Kemenristekdikti) which supported financial to this study through Teaching Industry Program for Diponegoro University. Furthermore, thank you to Center for Plasma Research (CPR) Diponegoro University Indonesia which supported all of the facilities for this Research.

Conflict of Interest : The authors have no conflicts of interest to report in regard to this manuscript.

\section{References}

1. M.J. Wargovich, HortScience 35, 573-575 (2000).

2. S. Liua, I.M. Leea, U. Ajania, S.R. Colea, J.E. Buring, J.A. Mansona, Intl. J. Epidemiol, 30, 130135 (2001).

3. FAO. 2013. FAOSTAT data. http://www.fao.org.

4. J. S. Dias, Acta Hort. 921, 153-170 (2011).

5. J.G. Kim, A.E. Yousef, M.A. Khadre, Adv. in Food and Nutrition Research, 45, 167-218 (2003).

6. C. O'Donnell, B.K. Tiwari, P.J. Cullen, R.G. Rice, Ozone in Food Processing, 1 (2012).

7. FDA (1995) Fed. Reg., 60: 57 075-130.

8. H. Tomiyasu, H. Fukutomi, G. Gordon, Inorg Chem 2 :19, 2962-2966 (1985).

9. M.A. Khadre, A.E. Yousef, J.-G. Kim, Jfs: Concise Reviews In Food Science, 66:9 (2001).

10. L. Zhang, Z. Lu, Z. Yu, X. Gao, Food Control J. 16, 279-283 (2005).

11. A. Garcia, J.R. Mount, P.M. Davidson, J. Food Science 68:9, 2747-2751 (2003).

12. N. Singh, R.K. Singh, A.K. Bhunia, R.L. Stroshine, Lebensmittel Wissenschaft und Technologie 35, 720-729 (2002).

13. S. Koseki, K. Yoshida, S. Isobe, K. Itoh, J. Food Protection, 64:5, 652-658 (2001).

14. J.G. Kim, A.E. Yousef, G.W. Chism, J. Food Safety 19, 17-34 (1998).

15. J.M. Ogawa, A.J. Feliciano, B.T. Manji, J. Phytopathology 80, 1020 (1990).

16. T.R. Bott, J. Food Control, 2, 44-49 (1991).

17. A. Allende, F.A. Tomás-Barberán, M.I. Gil, Trends in Food Science and Technology, 17, 513-519 (2006).

18. B. Daniela, V.B. Gustavo, J. Food Control, 29, 8290 (2013).

19. P.M.A. Toivonen, M. Sweeney, J. Agric. Food Chem. 46, 20-24 (1998).

20. G.A. King, S.C. Morris, J. Am. Soc. Hort. Sci. 119, 270-275 (1994).

21. H. Zhuang, D.F. Hidebrand, M.M. Barth, J. Agric, Food Chem. 43, 2585-2591 (1995).

22. H. Zhuang, D.F. Hidebrand, M.M. Barth, J. Agric, Postharvest Biol. Technol. 10, 49-58 (1997).

23. J.B. Pogson, S.C. Morris, J. Am. Soc. Hort. Sci. 122, 553-558 (1997). 